\title{
Negotiating demands of social change in young and middle-aged adults from Poland
}

Tomasik, Martin J ; Silbereisen, Rainer K ; Lechner, Clemens M ; Wasilewski, Jacek

\begin{abstract}
Social and economic changes on the societal macro level, such as globalization, pluralization, and demographic shifts, create new demands that produce stress and require behavioral adaptation. In this large-sample correlational study, which replicates a similar study previously conducted in Germany, we investigated how young and middle-aged adults from Poland $(\mathrm{N}=2,541)$ negotiated these demands. Dependent variables were engagement and disengagement strategies as defined by the motivational theory of life span development. By using planned contrasts between engagement (selective primary, selective secondary, and compensatory primary control) and disengagement (compensatory secondary control) in a repeated-measures ANOVA, we found a strong $\left({ }^{2}=.48\right)$ preference for engagement over disengagement. Multivariate regression analyses revealed that the engagement and disengagement strategies were only modestly related to sociodemographic characteristics such as age, gender, employment, and partnership status $(.00<||<.13)$. Primary appraisal of the demands in terms of challenge/threat and gains/losses were correlated with engagement and disengagement $(.01<||<.16)$, but direction and size of the coefficients differed from what was previously found in Germany. Secondary appraisal of the demands in terms of their controllability $(.04<||<.21)$ and the perceived load of demands itself $(.12<||<$ $.22)$ turned out to be the most relevant predictors of the engagement and disengagement strategies. By contrasting these results against earlier findings obtained in Germany, we argue that the differences in how people negotiate social change in the two countries are rooted in their different systems of welfare and social security.
\end{abstract}

DOI: https://doi.org/10.1037/a0033935

Posted at the Zurich Open Repository and Archive, University of Zurich

ZORA URL: https://doi.org/10.5167/uzh-92732

Journal Article

Originally published at:

Tomasik, Martin J; Silbereisen, Rainer K; Lechner, Clemens M; Wasilewski, Jacek (2013). Negotiating demands of social change in young and middle-aged adults from Poland. International Journal of Stress Management, 20(3):222-253.

DOI: https://doi.org/10.1037/a0033935 
Running head: NEGOTIATING SOCIAL CHANGE IN POLAND

Negotiating Demands of Social Change in Young and Middle-Aged Adults from Poland Martin J. Tomasik University of Zurich, Switzerland Rainer K. Silbereisen

Friedrich Schiller University of Jena, Germany

Clemens M. Lechner

Friedrich Schiller University of Jena, Germany

Jacek Wasilewski

Warsaw School of Social Sciences and Humanities, Poland 


\begin{abstract}
Social and economic changes on the societal macro level, such as globalization, pluralization, and demographic shifts, create new demands that produce stress and require behavioral adaptation. In this large-sample correlational study, which replicates a similar study previously conducted in Germany, we investigated how young and middle-aged adults from Poland $(N=2,541)$ negotiated these demands. Dependent variables were engagement and disengagement strategies as defined by the motivational theory of life-span development. By using planned contrasts between engagement (selective primary, selective secondary, and compensatory primary control) and disengagement strategies (compensatory secondary control in terms of self-protection and distancing) in a repeated-measures ANOVA, we found a strong $\left(\eta^{2}=.48\right)$ preference for engagement over disengagement. Multivariate regression analyses revealed that the engagement and disengagement strategies were only modestly related to sociodemographic characteristics such as age, gender, employment, and partnership status $(.00<|\beta|<.13)$. Primary appraisal of the demands in terms of challenge/threat and gains/losses were correlated with engagement and disengagement $(.01<|\beta|<.16)$ but direction and size of the coefficients differed from what was previously found in Germany. Secondary appraisal of the demands in terms of their controllability $(.04<|\beta|<.21)$ and the perceived load of demands itself $(.12<|\beta|<.22)$ turned out to be the most relevant predictors of the engagement and disengagement strategies. By contrasting these results against earlier findings obtained in Germany we argue that the differences in how people negotiate social change in the two countries are rooted in their different systems of welfare and social security.
\end{abstract}

Keywords: demands; globalization; appraisals; control; coping; engagement; social change; pluralization; demographic shift. 


\section{Negotiating Demands of Social Change in Young and Middle-Aged Adults from Poland}

More than 20 years have passed since the major political and economic transitions in Central and Eastern Europe opened the floodgates for the development of new democracies and free-market economies. The ensuing transformation processes in the societies of this region brought about severe challenges, which were exacerbated by a surge in economic globalization, growing global interdependence, and the increased volatility of markets (see Mills \& Blossfeld, 2003). Changes were also evident in increased individualization based on less commitment to traditional family and work styles, and pluralization, with a wider range of life choices (Tomasik \& Silbereisen, 2009), as well as a demographic shift stemming from low birth rates and greater longevity (Tomasik \& Silbereisen, in press). More recently, integration into the European Union and market shocks due to the financial and economic crisis of 2008/09 have challenged the political and economic systems.

The fast pace and global scope of contemporary social change is unprecedented in history and has spurred new theory-building and research on possible transactions between the context and the individual (e.g., Sinclair, Sears, Probst, \& Zajack, 2010; Tomasik \& Silbereisen, 2012b). Some theorists (e.g., Pinquart \& Silbereisen, 2008) suggest that social change at the macro level first needs to cascade through the various contexts of development down to the micro level, where it translates into everyday psychological experiences. Silbereisen and colleagues (Pinquart \& Silbereisen, 2008; Tomasik \& Silbereisen, 2009) have employed the concept of perceived demands to describe novel obligations at the micro level that result from the new social conditions. In the micro context of work, such new demands might comprise increased uncertainty with respect to career planning, actual job loss, a decline in workplace conditions, and economic hardship.

The investigation of such topics has a long tradition in research on stress and coping (e.g., Voydanoff, 1990), which sometimes takes an explicit multilevel perspective (Sinclair et al., 2004). Applying a stress and coping perspective, Pinquart and Silbereisen (2008) argued that demands, and especially their accumulation over time and across different domains of life, represent stressors that can 
overtax the adaptive capacities of the individual and thus eventually compromise successful functioning. In support of this reasoning, several studies have demonstrated that a high load of perceived demands is associated with higher depressive symptoms or lower satisfaction with life (e.g., Grümer \& Pinquart, 2011; Lechner, Tomasik, Silbereisen, \& Wasilewski, in press).

The central research question addressed in this paper is how young and middle-aged adults from Poland negotiate the stressful demands of social change in the domain of work. Do they try to cope with these pressures in an engaged and problem-focused way or do they tend to disengage and withdraw? What predicts inter-individual differences in engagement and disengagement? And does a high load of demands promote or inhibit engagement with them? In this paper, we answer these questions resorting to data from a study conducted in Poland in 2009. The Polish study is a partial replication of study conducted in Germany in 2005 by Tomasik, Silbereisen, and Pinquart (2010). In comparing the two countries, we followed the strategy employed by Kohn (2010; Kohn, Slomczynski, \& Schoenbach, 1990) who replicated established findings from one context into another one in order to determine the sensitivity of the results to contextual variations.

Poland, as a transformation society, is particularly suited for this kind of replication due to the geographical proximity to Germany and membership in the European Union. In addition, the Poland's regions, like Germany's, are economically heterogeneous and the countries share some similar historical experiences, such as the political transition in 1989 and the economic transformation thereafter. In spite of all these similarities, there are also differences that are probably important for our study. Germany and Poland, for instance, have different regulations concerning social benefits in case of unemployment, serious illness, or disability with generally less generous support in Poland as compared to Germany.

Thus, in Poland demands can pose a more substantial threat to one's livelihood than in Germany

\section{Negotiating Demands of Social Change}

Individuals are neither passive recipients nor victims of change-related demands. Rather, they negotiate their own development by setting up and pursuing goals, and by adjusting these goals to 
changing opportunities and constraints (e.g., Eccles \& Wigfield, 2002). A high load of demands can be regarded as the beginning of a longer process of adaptation in which different aspects of individual and collective agency play an important role (Pinquart \& Silbereisen, 2008). From a stress and coping perspective, demands can be considered as stressors that threaten resources that individuals aim to conserve (Hobfoll, 1989), as life strains rooted in the social structure (Pearlin, Menaghan, Lieberman, \& Mullan, 1981), or as representing subjective discrepancy appraisals in terms of a harm or loss that has already occurred or a threat that is likely to occur (see Lazarus, 1991). These appraisals then are a starting point for the coping process that always involves some kind of personal agency (see Thoits 2006). For the domain of work, these processes have been well described and theoretically elaborated by Latack, Kinicki, and Prussia (1995) against the backdrop of the cybernetic theory of coping by Edwards (1992). Latack at al. have demonstrated how discrepancy appraisals, together with the evaluation of one's coping resources, may comprise striving for control, escape and withdrawal, as well as some forms of compensatory action, such as seeking social support.

In this study, we chose the motivational theory of lifespan development by Heckhausen, Wrosch, and Schulz (2010) as a general framework to classify and evaluate how individuals deal with the demands of social change. The authors of this theory distinguish between primary control, which is targeted at changing the external world, and secondary control, which is directed towards the self. Both primary and secondary control may have either a selective (i.e., focusing one's resources to negotiate a particular demand) or a compensatory (i.e., buffering negative effects failure in negotiating a demand) functionality, which results in the four following basic modes of adaptive behavior:

Selective primary control (SPC) addresses the investment of personal resources, such as ability, time, and effort in order to master a demand. Take as an example the demand that one's own career path has become more difficult to plan due to contract work, unpredictable layoffs, and so on. An SPC way to deal with this demand would be to invest more energy in finding a job that, perhaps requires higher qualifications, but is more secure. Selective secondary control (SSC) serves motivational commitment 
through the enhancement of perceived positive consequences after mastery of the demands and through enhanced appraisal of one's own capacity for control. In our example, if an individual repeatedly procrastinates engaging in a job search, he or she could maintain motivation by imagining over and over again how happy he or she will be after obtaining a more secure job. At the limits of personal resources, compensatory primary control (CPC) can be activated. This control strategy comprises seeking social support as well as looking for alternative means and solutions. In our example, this could be asking a professional career consultant for assistance in writing a persuasive application letter.

Whereas SPC, SSC, and CPC above represent goal-engagement strategies in terms of a productive response to the stressors, compensatory secondary control (CSC) represents a disengagement strategy. Two different aspects of CSC can be distinguished. Strategies of self-protection (CSC I) aim at the protection of the motivational potential and emotional well-being of the individual. In our example, individuals could blame the local labor market for not offering enough jobs that are secure or compare themselves with others who are even worse off. Strategies of distancing (CSC II) help to ease the final disengagement from goals when, for example, meeting certain demands is no longer feasible. In our example, individuals could try to downplay the personal significance of career progress, thus making it easier to disengage from the goal of advancement. ${ }^{1}$

\section{Summary of Previous Empirical Research}

Although many researchers have investigated how individuals deal with single aspects of social change, such as job loss and unemployment (e.g., Waters, 2000) or new relationship stressors (e.g., Seiffge-Krenke, 2011), only a few studies have addressed how individuals deal with an accumulation of demands that result from changes at the macro level. Seiffge-Krenke et al. (2010), for example, analyzed how adolescents from different countries dealt with uncertainty concerning different aspects of the future, such as occupational planning, social expectations, and environmental damage. Essentially, the study showed a preference for active (i.e., SPC) and internal (i.e., SSC) coping over withdrawal (i.e., $\mathrm{CSC}$ ). Adolescents who were living in families with low socioeconomic status reported the highest 
levels of withdrawal; there were only small country differences for all three coping styles (although other studies, e.g., Frydenberg et al., 2003, found larger country differences when investigating countries more diverse in their cultural and economic background).

In a study investigating the demands of social change in a German sample, Tomasik, Silbereisen, and Pinquart (2010) found a strong preference for engagement over disengagement strategies. Furthermore, how individuals negotiated demands of social change had little to do with basic sociodemographic variables, but rather with the primary and secondary appraisal of the demands. A stronger primary appraisal of the demands of social change as challenges (as opposed to threats) was associated with more engagement and less disengagement; a stronger primary appraisal of the demands as associated with gains (as opposed to losses) was associated with more engagement; and a stronger secondary appraisal of demands in terms of personal controllability was associated with more engagement and less disengagement. Beyond these associations, the load of perceived demands predicted a higher score on all control strategies.

Some of these findings were replicated by Tomasik and Silbereisen (in press) in a sample of older adults with regard to the demands of social change related to active aging (i.e., engagement in lifelong learning or volunteering). Higher internal control beliefs predicted higher SPC and SSC control as well as lower CSC. There is evidence that higher loads of demands predict more engagement, that more perceived opportunities predict less disengagement, and that both engagement and disengagement depend on primary and secondary appraisal processes.

\section{Hypotheses}

There are two bases for the hypotheses developed in this paper: First, following Heckhausen's motivational theory of lifespan development (Heckhausen et al., 2010), we assumed the preeminence of primary control in striving to negotiate demands of social change and expected that a higher endowment of resources will be generally associated with more engagement and less disengagement in dealing with the demands of social change. Second, we built on findings from previous research on negotiating 
demands of social change in Germany as published by Tomasik, Silbereisen, and Pinquart (2010) as summarized above.

\section{Preference for Goal Engagement}

The motivational theory of lifespan development proposes that individuals are motivated to maintain, or enhance their primary control capacity within the central domains of life (see Heckhausen \& Schulz, 1999). In general, maximization of primary control is best achieved by exerting goal engagement strategies unless opportunities for goal engagement are severely constrained (Tomasik, Silbereisen, \& Heckhausen, 2010; Tomasik \& Silbereisen, 2012a). Since work is one of the central domains of adult life, and demands in this domain represent a substantial peril to successful development, we hypothesized that individuals will try to negotiate them more in terms of goal engagement and less in terms of goal disengagement (Hypothesis 1). As we cannot assume that opportunities for goal engagement are severely constrained for a substantial majority of the population, negotiating demands in terms of goal engagement is, at least on average, most promising in order to maintain and to expand the individual's primary control capacity.

\section{Inter-individual Differences in Primary and Secondary Control Strategies}

Age. Although there is research showing clear changes in primary and secondary control strategies as a function of age, the effects usually tend to appear in age groups that are substantially older than those that we have investigated. We thus did not expect any age effects, but still considered age as a covariate in our analyses.

Gender. There is also some research showing that men and women tend to approach problems differently, be it more due to dispositional (e.g., Taylor et al., 2000) or situational factors (e.g., Rosario, Shinn, Morch, \& Huckabee, 1988). In a meta-analysis on gender differences in coping across various types of stressors, Tamres, Janicki, and Helgeson (2002) found that women, as compared to men, were more likely to use various ways of coping, including those strategies that come close to our conceptualization of primary and secondary control. The effect sizes were small, but consistent, and 
remained stable after considering gender differences in the appraisal of a stressor. Concerning the way that men and women negotiate the demands of social change, Tomasik, Silbereisen, and Pinquart (2010) found that women reported more engagement control strategies (which is consistent with the metaanalysis cited above), but at the same time less disengagement (which is contrary to the meta-analysis cited above). It seems that women are more determined to cope with demands of social change, which might have to do with gender inequality in terms of the relative disadvantage for women in access to a wide range of resources (see Tesch-Römer, Motel-Klingebiel, \& Tomasik, 2008) that makes it paramount for women to invest more than men in order to successfully compete in the labor market. Based on this reasoning and on the previous findings in Germany by Tomasik, Silbereisen, and Pinquart (2010), we hypothesized that women will report more engagement and less disengagement strategies as compared to men (Hypothesis 2).

Occupational status. Theoretical considerations and empirical findings suggest that negotiating demands of social change to some extent depends on the occupational status of an individual or, more specifically, whether someone is employed, unemployed but seeking a job, or outside the labor market. Employment can be considered as an "institutional filter" (Mills \& Blossfeld, 2003) that protects the individual from the negative effects of social change and provides access to valuable resources that are relevant for dealing with the respective demands because employment is associated with higher income, better legal protection, acquired privileges, a higher degree of organization, and support by labor unions. However, there is also evidence that unemployed individuals, although probably endowed with fewer institutional resources, do report similar levels of engagement and disengagement with demands as employed individuals; this is probably due to the fact that, for unemployed individuals, mastering demands is more relevant and also more urgent (see Tomasik, Silbereisen, \& Pinquart, 2010). Contrary to this group, those who are outside the labor market (e.g., homemakers) do not have either the institutional resources or the urgency to master the demands of social change. Consequently, we hypothesized that both employment and unemployment will be associated with more engagement and 
less disengagement than being outside the labor market (Hypothesis 3).

Relationship status. Bodenmann's (1995) notion of “dyadic coping” suggests that coping can take place within the relationship context. Having a partner as opposed to being single, separated, divorced, or widowed can be a significant resource in negotiating demands; however, it is difficult to determine whether it is important to have an intimate partner or whether the legal status of a marriage as opposed to cohabitation makes the difference (see Marcussen, 2005). We expected that the question of whether or not one has an intimate partner makes the difference, as partners are able to provide emotional support regardless of their legal status, and perceived emotional support has been shown to be a multi-functional resource in negotiating various kinds of stressors (Kessler \& McLeod, 1985). Thus, we hypothesized that those without a partner (i.e., single, divorced, separated, or widowed) will report lower levels of engagement and higher levels of disengagement as opposed to other marital-status groups (Hypothesis 4).

Primary and secondary appraisals. Whether and to what extent an individual will try to overcome demands of social change in terms of engagement and disengagement is not related only to his or her access to resources (which we have tried to capture by the status variables described above). What is probably more decisive is the appraisal of these factors (see Martin \& Westerhof, 2003). Lazarus and Folkman (1984) distinguish between primary appraisal and secondary appraisal. Primary appraisal refers to cognitions regarding the impact of demands for the individual; secondary appraisal refers to cognitions concerning an individual's resources to deal with the demands. Previous research has demonstrated that appraisals are crucial for understanding how individuals deal with the demands of social change (see Tomasik, Silbereisen, \& Pinquart, 2010).

Concerning primary appraisals, we assumed that individuals may regard change that they experience as a challenge or as a threat and either focus on the gains or on the losses that such change entails. Literature on stress and coping shows that the primary appraisal of a stressor as a challenge is associated with approaching coping from a problem-focused perspective (e.g., McCrae, 1984). 
Similarly, a person who perceives gains will be more problem-focused than one who expects losses (e.g., Wurm, Tomasik, \& Tesch-Römer, 2010). We thus hypothesized that more positive primary appraisal of demands as challenging and as associated with gains will predict more engagement and less disengagement among our sample (Hypothesis 5).

Secondary appraisal seems to have an additional and independent effect on the subjective responses to stress (e.g., Folkman. Lazarus, Dunkel-Schetter, DeLongis, \& Gruen, 1986). A central aspect of secondary appraisal is the perceived controllability of a stressor (Lazarus \& Folkman, 1984). According to Valentiner, Holohan, and Moos (1994), the perceived controllability of a stressor prompts the choice of coping strategies that fits the situation. The literature provides substantial empirical evidence that individuals who feel in control are more likely to use problem-focused strategies and less likely to use emotion-focused strategies (e.g., Folkman et al., 1986; Scheier, Weintraub, \& Carver, 1986). We thus hypothesized that participants who report a higher perceived controllability of the demands will report more engagement and less disengagement (Hypothesis 6).

Demands of social change. Until now, we have basically considered status indicators of institutional resources (gender, occupational and partnership status), as well as primary and secondary appraisals of demands of social change as predictors of engagement and disengagement with these demands. However, we were also specifically interested in examining the direct effect of demands on control strategies. Research in stress and coping has demonstrated that higher levels of stress are generally associated with more coping efforts (e.g., Lazarus \& Folkman, 1984). Tomasik, Silbereisen, and Pinquart (2010) demonstrated that this also holds true for demands of social change, finding positive associations between the load of demands that individuals experience and all control strategies, be it those representing engagement or those representing disengagement. We hypothesized that this finding will be replicated in the Polish sample (Hypothesis 7).

\section{Summary of the Hypotheses}

To sum up, we posed the following hypotheses: 
1) Individuals will negotiate demands more in terms of goal engagement and less in terms of goal disengagement.

2) Women will report more engagement and less disengagement as compared to men.

3) Individuals who are employed or unemployed will report more engagement and less disengagement as compared to those who are outside the labor market.

4) Individuals who are in an intimate relationship will report more engagement and less disengagement as opposed to those who are not.

5) Individuals who appraise demands as challenges or associated with gains will report more engagement and less disengagement.

6) Participants who perceive a higher controllability of the demands will report more engagement and less disengagement.

7) Individuals who perceive a higher load of demands will report more engagement and more disengagement.

\section{Method}

\section{Sample and Procedure}

The sample analyzed was part of the research project Sociological and Psychological Determinants of Negotiating Rapid Social Changes conducted at the Warsaw School of Social Sciences and Humanities in Poland (PI: Prof. Dr. Jacek Wasilewski), as part of the international collaboration with the Jena Study on Social Change and Human Development in Germany (PI: Rainer K. Silbereisen; for details, see Silbereisen \& Pinquart, 2008). The current study, conducted in Poland, was a replication of the study conducted in Germany. All possible steps were taken to ensure the highest level of compatibility between the two studies. Both studies were conducted only a few years apart, in exactly the same way, and using exactly the same material. Furthermore, the material was translated back and forth and carefully adapted to the Polish context so that we could basically rule out the possibility of substantial period effects and methodological artifacts. 
In Poland, respondents were drawn from two Western (Pomerania and Lower Silesia) and two Eastern (Lublin and Subcarpathia) administrative districts. For sampling the respondents, each district was split further into smaller regional units, and within each district, sampling points were randomly selected from the registrar's office. Starting with these initial sampling points, respondents were contacted based on a random route procedure and asked whether they were willing to be interviewed. After they gave their informed consent, an interviewer of a professional survey institute conducted standardized face-to-face interviews at the participants' homes. An equal number of inhabitants were interviewed in each administrative district so that, in total, more than 3,000 interviews were performed in the spring of 2009. For the present analyses, we excluded all subjects who were still in school because work-related demands are not yet relevant for them. The resulting sample thus comprised $N=$ 2,541 young and middle-aged adults between 16 and 46 years $(M=32.0 ; S D=8.0)$. Approximately $50.7 \%$ were male $(n=1,289), 27.5 \%$ were from Lower Silesia $(n=698), 25.3 \%$ from Pomerania $(n=$ 642), 23.8\% from Subcarpathia $(n=606)$, and 23.4\% from Lublin district $(n=595)$.

According to the survey institute, the response rate ranged between 47.17 and $53.63 \%$ in the four regions. As a measure of sampling quality, we additionally compared the composition of the sample with official registry data from the Polish Central Statistical Office with regard to age, gender, and marital as well as occupational status. Results of this analysis showed that the sample was representative of the same-aged population in the four administrative districts in terms of age and gender. Unemployed individuals, who have a higher likelihood of being at home, were slightly overrepresented in our sample while married individuals, who are more often employed full time, were slightly underrepresented. A similar pattern of non-response also emerged in the German study.

\section{Variables}

Demands. Work-related demands of social change were assessed by the six items presented in Table 1. Details on the selection of the demand items and their macro-structural origin are provided by Tomasik and Silbereisen (2009). The item wordings are presented in Table 1 together with the items' 
mean score in the study sample. Respondents were prompted to "consider the past five years" and then asked to rate the demands of social change on a scale from 1 (does not apply at all) to 7 (fully applies). Based on all six items, a mean composite scale was formed. The mean score on demands in the study sample was $M=4.31(S D=1.64)$ and the scale's internal consistency was high $(\alpha=.89)$. Tomasik and Silbereisen (2009) obtained similar results in a study conducted in Germany. Tomasik, Sijko, Silbereisen, and Wasilewski (2013) report associations between individual demands of social change and regional indicators of economic prosperity that support the validity of the scale (e.g., a higher demand load was prevalent in regions that were declining economically).

[Insert Table 1 about here]

Primary and secondary control. A scale introduced by Tomasik, Silbereisen, and Pinquart (2010), which is based on the framework of the motivational theory of lifespan development (Heckhausen et al., 2010), was used to assess primary and secondary control strategies with regard to demands of social change. Respondents were asked to respond to 15 control strategy items (i.e., three per strategy) immediately after having given their responses to the six demands in the domain of work. This procedure was repeated for demands in the domain of family and once again for demands in the domain of leisure (which, however, we did not consider here) with the same 15 control strategy items. The control strategy scales were assessed by paper-and-pencil in the otherwise oral interview. Respondents were asked to respond to each item on a scale ranging from 1 (does not apply at all) to 7 (fully applies).

A latent measurement model was set up for each control strategy. To account for the multidomain structure of the assessment, the model depicted in Figure 1 was used. The latent factor $\mathrm{D}_{0}$ used hereinafter refers to a control strategy in the domain of work that was set as the reference category in the model. The latent difference factors $\mathrm{D}_{1-0}$ for family and $\mathrm{D}_{2-0}$ for leisure were used to calculate the domain specificity of the control strategies, but otherwise were not used in the present analyses. Note that the demands assessed in the domains of family and leisure all referred to uncertainty due to social 
change. The repeated measurement of the single items was accounted for by M-1 method factors that represent a more elegant alternative to modeling correlated errors.

We used full-information maximum likelihood to estimate the models. Besides calculating the $\chi^{2}$-statistic, fit was evaluated using two indices for absolute discrepancy (Root Mean Square Error of Approximation [RMSEA] and Standardized Root Mean Square Residual [SRMR]) and one index comparing the target model with a null model fairly independent of the sample size (Non-Normed Fit Index or Tucker-Lewis-Index [TLI]). An excellent model fit is indicated by a non-significant $\chi^{2}$-test (which is rarely obtained in large samples), RMSEA <.01 (MacCallum, Browne, \& Sugawara, 1996), SRMR $<.05$ (Steiger, 1990), and TLI close to 1.00 , although TLI $>.96$ is still considered satisfactory when another indicator is below the respective threshold (Hu \& Bentler, 1999). The four indices were selected because they reflect different aspects of model fit and are routinely used in structural equation modeling.

\section{[Insert Figure 1 about here]}

The model for SPC (sample item: "I am also prepared to make a great effort in order to find a good solution") replicated the data structure without a significant deviation $\left(\chi^{2}[13]=17.71 ; p=.17\right)$ and other indicators also suggested a good fit $(\mathrm{RMSEA}=.011 ; \mathrm{SRMR}=.010 ; \mathrm{TLI}=.999)$. The domainspecific variance in the work domain was $\psi=.35$, indicating a strong trait component, that is, only one third of the variance in this measure was attributable to the life domain, whereas the rest was same across the life domains assessed. Factor loadings were in the range of $.75<\lambda<.78$. The model for SSC (sample item: "I tell myself, time and time again, that I can manage it if only I set my mind on it") could not replicate the data without a significant deviation $\left(\chi^{2}[13]=25.82 ; p=.02\right)$. Other indicators, however, suggested a good model fit according to current standards in the field (RMSEA = .018; SRMR $=.008 ; \mathrm{TLI}=.996)$. Because it is a regular practice to report findings based on similarly fitting models, the measurement model was accepted. The work domain-specific variance was again moderate with $\psi=$ .34 and factor loadings were in the range of $.66<\lambda<.78$. Likewise, a significant deviation was found for 
the latent measurement model set up for CPC $\left(\chi^{2}[13]=49.16 ; p<.001\right.$; sample item: "If I get stuck, then I take advantage of all help I get to make headway"), although the model also fit the data satisfactorily $(\mathrm{RMSEA}=.030 ; \mathrm{SRMR}=.013 ; \mathrm{TLI}=.991)$ and was thus accepted. The domain specific variance of this scale in the domain of work $(\psi=.32)$ was also moderate. Factor loadings were in the range of .74 $<\lambda<.79$. CSC was assessed with two independent scales. The first scale focused on the function of CSC to protect motivational and emotional resources of the individual in case of failure. The model for the self-protective CSC (sample item: "If I can't handle these changes then I search for grounds not to have to give myself the blame") also fit the data satisfactorily $\left(\chi^{2}[15]=25.01 ; p<.05\right.$; RMSEA $=.015 ;$ SRMR $=.009 ; \mathrm{TLI}=.998)$ and was accepted. Domain specific variance was $\psi=.18$, and thus again quite low, and factor loadings were in the range of .66 $<\lambda<.68$. The second aspect of CSC was assessed with items indicating distancing from demands of social change (sample item: "If I can't find a solution, then I put the problem to the back of my mind"). The model fit the data well ( $\chi^{2}[14]$ $=21.02 ; p=.10 ; \mathrm{RMSEA}=.013 ; \mathrm{SRMR}=.008 ; \mathrm{TLI}=.999)$ and was thus accepted. Domain specific variances was $\psi=.22$. Factor loadings were in the range of $.71<\lambda<.73$. Due to the large number of homogeneous items necessary to determine the latent scores, the reliability of these measures always exceeded $\rho>.90$.

The five scales related to the domain of work fit a five-factor confirmatory model well $\left(\chi^{2}[80]=\right.$ $527.02 ; p<.01 ; \mathrm{RMSEA}=.043 ; \mathrm{SRMR}=.036 ; \mathrm{TLI}=.964)$ and showed a pattern of correlations that is consistent with theory. The three-goal engagement scales (SPC, SSC, and CPC) were positively correlated with each other $(.69<r<.71)$, and so were the two disengagement scales $(r=.53)$. Associations with scales representing goal engagement on the one hand with scales representing goal disengagement on the other hand were small $(-.12<r<.07)$ with one important exception. Selfprotection as an aspect of CSC was positively associated with SSC and CPC to a moderate degree (both $r=.23)$. The latter finding might indicate that self-protective attributions may also be used for goal engagement, for example when opportunities for goal engagement are temporarily blocked. 
Despite the high correlations between the scales, we decided to analyze them separately. We did so in order to identify possible scale-specific results and, more importantly, to maintain compatibility with the parallel analysis performed on the German sample by Tomasik, Silbereisen, and Pinquart (2010).

Occupational status. Respondents reported their current employment status. Based on the criteria of the International Labor Office (ILO) they were then assigned to the group of (a) employed (n $=1,581$ or $62.2 \%$ ), (b) unemployed who were searching for a job in the last four weeks and willing to accept a job offer within the next two weeks, which follows the criteria for unemployment introduced by the ILO; $\mathrm{n}=404$ or $15.9 \%$ ), or (c) people outside the labor market ( $\mathrm{n}=556$ or $21.9 \%$ ). The latter group comprised homemakers, men and women on parental leave, and all other unemployed who did not meet the ILO criteria for unemployment.

Partnership status. In our sample, 1,429 (56.2\%) respondents were married, 417 (16.4\%) were cohabiting, 438 (17.2\%) were single, and 257 (10.1\%) were separated, divorced, or widowed.

Primary appraisal. Two different aspects of primary appraisals were assessed. First, three items were used to capture the perceived gains and losses associated with new demands of social change. Using a "structure alternative format" to reduce social desirability bias, respondents were asked to rate, on a 7-point scale, which of the alternative statements best described their opinion. The respective items were, "Some people say that they have more problems thanks to new demands; still others say that they can solve old problems thanks to new demands," "Some people say that they are less able to enjoy their life due to new demands; still others say that they enjoy life more due to new demands," and "Some people say that new demands lead to family conflicts; still others say that new demands strengthen family cohesion.” Second, referring to Lazarus' (Lazarus \& Folkman, 1984) concept of primary appraisal, we used an item to span a dimension between challenge and threat ("Some people say that they experience new demands as a challenge; still others say that they experience new demands as a threat."). The challenge-threat item was recoded so that higher values indicated a higher orientation 
towards challenge $(M=4.00 ; S D=1.54)$. A gains-losses mean composite scale was computed from the other three items with higher values, indicating an orientation towards gains $(M=3.99 ; S D=1.36)$. The internal consistency of the gains-losses scale was $\alpha=.83$ and thus quite satisfactory for the small number of items. The two dimensions, challenge-threat and gains-losses, were only moderately correlated by $r=.10$.

Secondary appraisal. Controllability as an indicator of secondary appraisal was assessed immediately after respondents rated all demands of social change. They were asked to indicate on a seven-point scale how well they "felt prepared to meet all these changes mentioned." This item thus represents the "agent-means" aspect of control, which is sometimes also referred to as "capacity belief." This item's mean was $M=4.50(S D=1.43)$. It was slightly correlated with the challenge-threat appraisal by $r=.08$, and by $r=.10$ with gains-losses appraisal.

Age and gender. Respondents' age in years and gender were assessed by self-report.

\section{Results}

Prior to all analyses, we tested the assumptions of multiple regression, checking for uni- and multivariate outliers, normality, linearity, and homoscedasticity. Although all dependent variables were significantly skewed and deviated significantly from a normal distribution according to the Komolgorov-Smirnov test, skewness did not exceed $g=.51$ for any of the variables. In addition, a graphical inspection via Q-Q-plots revealed that the variables were still approximately normally distributed. No outliers or indications of nonlinearity or significant heteroscedasticity were found. Thus, we concluded that our data sufficiently met the assumptions of multiple regression.

Before testing our hypotheses, we performed some descriptive analyses. The correlations between all study variables are presented in Table 2, and a descriptive comparison between the Polish and the German samples is provided in Table 3.

[Insert Tables 2 and 3 about here]

\section{Preference for Goal Engagement}


In order to test our hypothesis about a general preference for goal engagement over goal disengagement control strategies (Hypothesis 1), we performed a repeated measures analysis of variance with planned contrasts. The five sub-scales measuring control strategies concerning work-related demands served as a within-subject factor. The three goal engagement scales, consisting of SPC $(M=$ $5.40 ; S D=.97), \operatorname{SSC}(M=5.22, S D=.94)$, and $\mathrm{CPC}(M=5.20, S D=.98)$ were contrasted against the two goal disengagement scales of self-protection $(M=4.25, S D=1.07)$ and distancing $(M=3.96, S D=$ 1.12). The analysis showed a moderate-to-strong effect, $F_{(1,2540)}=2298.42, p<.001$, partial $\eta^{2}=.48$. Thus, our hypothesis that goal engagement is preferred over goal disengagement was supported.

\section{Inter-individual Differences in Control Strategies}

In order to test our hypotheses concerning demographic indicators and appraisals, a set of linear models with three sequential steps of analysis were performed using the REGRESSION module of SPSS 19.0 for Mac. In Model 1, all demographic variables (i.e., age, gender, employment status, and partnership status) were entered into the regression equation. The categorical variables (employment status and partnership status) were recoded into contrast (or dummy) variables prior to the analyses. In Model 2, the three appraisal variables were added to the regression equation. In Model 3, finally, the average load of work-related demands was added as a predictor to discover whether the level of perceived stress has an effect beyond demography and appraisals. This procedure was repeated for each of the five control strategy scales and the results are summarized in Table 4. Cell entries represent standardized regression coefficients $(\beta)$. In the following section, we will present the results in the order of the hypotheses.

[Insert Table 4 about here]

Socio-demographic variables. Although we had no specific hypothesis with regard to age, we found that older participants generally reported less engagement and less disengagement. When controlling for the load of demands, investing time and effort, and distancing were no longer significant, which suggests that age differences in control strategies are at least partly a function of age differences 
in the load of demands.

Concerning gender, we expected that women will report more goal engagement and less disengagement than men (Hypothesis 2). Both views were corroborated by the data, although the effect sizes were small. Compared to men, women reported investing more time and effort $(B=.01, \beta=.05)$, using more motivational strategies $(B=.01, \beta=.05)$, and seeking more support $(B=.01, \beta=.04)$, as well as using fewer distancing strategies $(B=.01, \beta=-.04)$ for dealing with work-related demands of social change. These gender effects remained consistent after adding the appraisal variables to the models; therefore, they cannot be attributed to gender differences in primary and secondary appraisals. However, the association between gender and CPC became nonsignificant when demands were also controlled for, suggesting that this association was due to differences in the load of demands that men and women experience.

We further hypothesized that, compared to being employed or unemployed, being outside the labor market will be associated with less goal engagement and more goal disengagement (Hypothesis 3). We indeed found consistent negative associations of being outside the labor market regarding all engagement strategies, although there was no such pattern for disengagement. In other words, being outside the labor market was associated with less effort to overcome work-related demands $(B=-.29, \beta$ $=-.12)$, fewer motivational strategies to support this effort $(B=-.23, \beta=-.10)$, and less social support seeking $(B=-.21, \beta=-.09)$. Thus, our hypothesis was supported regarding engagement, but not disengagement. On average, being outside the labor market was associated with about one-fifth to onethird fewer points on the engagement scales.

Our hypotheses concerning relationship status were based on the idea that not being in an intimate relationship is associated with having fewer social resources and thus will be associated with lower levels of engagement and higher levels of disengagement compared to cohabiting and married individuals (Hypothesis 4). This hypothesis was fully supported for all engagement strategies (with coefficients in the range of $-.16<B<-.29$ resp. $-.11<\beta<-.05)$, but not for disengagement strategies. 
The findings concerning relationship status thus approximate what we found for occupational status.

Appraisals. In our hypotheses concerning the role of primary (Hypothesis 5) and secondary appraisals (Hypothesis 6), we argued that appraisals of social change as a challenge (as opposed to a threat), as offering more gains (as opposed to losses), and perceiving a higher controllability of social change will be associated with more goal engagement and less goal disengagement. These hypotheses found only limited support in the current sample. As expected, challenge-threat appraisals were predictive of less self-protective attributions $(\beta=-.12)$ and less distancing $(\beta=-.06)$. Although we had expected positive associations, they were negatively associated with $\operatorname{SSC}(\beta=-.04)$ and $\operatorname{CPC}(\beta=-.05)$. Furthermore, they were not at all associated with SPC. Gains-losses appraisals were positively associated with self-protective attributions $(\beta=.13)$ and distancing $(\beta=.16)$, whereas we had expected negative associations. Unexpectedly, they were not at all associated with goal engagement. Results regarding perceived controllability were, however, in line with our hypothesis. Perceived controllability significantly predicted higher goal engagement and lower disengagement. As Table 3 shows, effect sizes were substantial, reaching $\beta=.20$ for SPC.

Demands. As hypothesized (Hypothesis 7), the average demand load had a unique effect on all five control strategy scales with more demands generally predicting more engagement with $(.12<\beta<$ $.22)$, and more disengagement from, work-related demands $(.17<\beta<.18)$. Furthermore, entering the average demand load as a predictor in the last step in the sequential regression analysis did not substantially change most of the regression coefficients or the $t$ values of the previous models for partnership status, being outside the labor market, and the demographic covariates.

Table 4 also comprises the explained variances for Model 1 (demography only), Model 2 (demography and appraisals), and Model 3 (demography, appraisals, and demands). An inspection of the coefficients (adjusted for shrinkage) yields four important insights. First, the amount of variance explained by demographic indicators alone was generally quite low. Second, considering appraisals slightly, but significantly, increased the share of explained variance in each of the five scales. Third, 
entering the demands in the last step again increased the amount of variance explained in each control strategy significantly; however, the improvement in $R^{2}$ as compared to Model 2 was more substantial for goal disengagement than for goal engagement strategies. Finally, the explained variance by all variables remained rather low in the final models.

\section{Discussion}

The aim of this paper was to investigate how young and middle-aged adults from Poland negotiate the demands of social change that they encounter in their everyday work life. We conceptualized the different ways of negotiating these demands based on the motivational theory of lifespan development (Heckhausen et al., 2010). Consistent with our hypothesis, we found a strong preference for engagement strategies over disengagement strategies. In terms of effect size, this was the strongest finding in our study. This replicates well what other studies (e.g., Seiffge-Krenke, 2011; Tomasik, Silbereisen, \& Pinquart, 2010) have found for different stressors in different samples. We conclude from this finding that individuals seem to consider demands of social change to be relevant enough to engage with and that demands are generally appraised as somehow controllable.

Next, we have analyzed inter-individual differences in primary and secondary control striving as a function of socio-demographic variables, primary and secondary appraisals, and the individual load of demands. Within the socio-demographic variables, we faced both expected and unexpected results. The finding that older people reported lower engagement and also lower disengagement strategies with respect to demands of social change in such a consistent way was unexpected. However, for two out of five scales, it turned out that the age effect in control strategies was partly attributable to age differences in the load of demands; therefore, we do not want to overstate this finding here.

Our hypotheses were supported with regard to gender, employment status, and partnership status. Women reported more engagement and less distancing from work-related demands, although this effect was not large in size. Women were more active in overcoming these demands, but we cannot determine, given our data, whether this gender effect reflects more dispositional differences between men and 
women (e.g., due to socialization) or more situational ones (e.g., due to different access to coping resources).

The effect of employment status on control strategies was also consistent with our hypothesis. We expected and found that those outside the labor market reported less engagement with demands. Compared to the employed, those outside the labor market put in less effort in mastering the demands of social change, which makes sense because mastering then is not so relevant for them, at least in the domain of work. Somewhat unexpected was the finding that, after controlling for the other sociodemographic variables, appraisals, and the load of demands, those who were unemployed reported less engagement and less self-protective strategies as compared to the employed. This finding might indicate the relative lack of resources of the unemployed as compared to the employed. Other studies have revealed that (e.g., Tomasik \& Silbereisen, 2009; Tomasik et al., 2013) that the unemployed face the highest load of demands by far. At the same time, however, they lack important institutional and personal resources that would allow them to negotiate demands of social change in an engaged manner.

Concerning partnership status, although our hypothesis was only partly supported, a meaningful pattern of findings emerged. Those who were single, divorced, or for any other reason did not have a partner, reported less engagement in the domain of work as compared to those who were married. Those who were cohabiting, however, did not differ from those who were married. Partnership had hardly any effect on disengagement, and all effects remained virtually the same when controlling for appraisals and demand load. These findings suggest that an intimate relationship (and not necessarily marriage, as suggested, for example, by Marcussen, 2005) might provide valuable resources for an engaged negotiation of demands and that this resource seems to function independently of how individuals appraise the demands of social change. From the literature, we know that perceived emotional support offered by a partner is most likely responsible for this effect (see Thoits, 1995). It might, however, also be that those without a partner engage less because they have to bear, on average, less responsibility for others, including children and in-laws, and thus have more freedom not to engage heavily in work- 
related demands. From our data, we cannot conclude whether these interpretations hold or which of the two is more plausible.

That disengagement was virtually independent of both occupational and relationship status is a finding that we did not expect and for which we do not have a clear explanation. The most plausible interpretation may be that disengagement is not driven by a lack of personal resources (as indicated by the status variables), but rather by a lack of external opportunities; this is a factor that we did not consider in our analyses. This interpretation is supported by the fact that controllability was much less relevant for disengagement than it was for engagement. Another plausible explanation might be that the status variables may have been incomplete indicators of resources that are associated with coping behaviors.

The results concerning the hypothesized effects of primary and secondary appraisals were also partly unexpected. Contrary to expectations, appraising demands more as a challenge was not related to SPC, was negatively related to SSC (before demand load was introduced) and to CPC; and appraisal as gains was unrelated to any of the engagement strategies. One explanation of this unexpected finding might be that the domain of work is so central and existential to the lives of most individuals that they engage with the demands regardless of how they appraise them. A complementary explanation that will be discussed below can be found in the Polish welfare system, which makes the engagement with demands of social change an existential concern for individuals.

The effects of appraising demands as challenges or gains on disengagement were mixed; challenges had the expected negative effects on disengagement, but gains were positively associated, contrary to expectations. Whereas the negative association between challenge appraisal and disengagement was theoretically expected, the positive association between gains appraisal and disengagement runs contrary to previous theoretical considerations and empirical findings. It could be that individuals who consider demands as associated with gains will disengage from them in order to selectively optimize their resources and make their resources available for mastering other demands that, 
if not met, could bring about greater losses. Yet, we have no definitive explanation for why someone who considers demands to "solve old problems," bring more "enjoy[ment in] life," and "strengthen family cohesion" (which was the actual item wording on the gains-losses-dimension) should be more likely to disengage from them.

Since the variance explained by considering primary appraisals was quite low, we have to conclude that it is almost irrelevant whether our participants consider the demands as a challenge or as a threat, or whether they think that demands are associated with gains or with losses. More relevant is the secondary appraisal of the demand or, more specifically, the question of whether or not they see themselves in control of mastering a demand. If they see themselves in control, they tend to engage more and disengage less.

The actual load of perceived demands that individuals reported was the strongest predictor of engagement and, particularly, disengagement in Poland. This was consistent with our expectation that the more individuals have to cope with, the more control strategies they will employ. Entering the load of demands into the regression equations did not change most of the previous effects of sociodemographic variables and appraisals; therefore, we can conclude that the load of demands has a unique effect on control strategies over and beyond the socio-demographic and appraisal variables. Interestingly, the weakest association in the models was with SPC and the strongest with SSC. As demands were also positively associated with disengagement strategies, these results in combination seem to support the conclusion that economic changes brought on by forces, such as globalization, limit the perceived utility of coping driven by personal mastery resources. ${ }^{2}$

\section{Similarities and Differences between Germany and Poland}

The results of our study, in part, resemble the results reported by Tomasik, Silbereisen, and Pinquart (2010) for a structurally equivalent sample of young and middle-aged adults from Germany. The most striking similarity between the two samples that we found was the preference for engagement over disengagement when negotiating work-related demands of social change; additionally, the 
secondary appraisal of demands (or perceived controllability), as well as the demand load itself, seemed to be similarly relevant for predicting primary and secondary control strategies in both Poland and Germany. Furthermore, age, gender, employment and partnership status played the same (albeit limited) role in both samples. These similarities suggest that at least some of our findings generalize across different countries.

At the same time, our results revealed substantial differences related to the role of primary appraisal of demands on the challenge-threat and the gains-losses dimensions. Primary appraisals have been much more important predictors of engagement and disengagement in Germany compared to Poland and, maybe more importantly, our results showed differences in the patterns of associations between the two countries. In Germany, both challenge-threat and gains-losses appraisals positively predicted engagement strategies; whereas, in Poland, they were virtually unrelated with engagement. Furthermore, gains-losses appraisals were unrelated to disengagement in Germany, whereas they were positively related to disengagement in Poland. Since meticulous care was taken to replicate the German study with this Polish study, it seems unlikely that differences in the study designs, the structural composition of the samples, or in the translation of the material can be responsible for such differences in the results.

We rather assume that the differences found in the data reflect true differences between Germany and Poland. Of course, both countries share strong similarities concerning, for example, their democratic political system and their basic social institutions. An important difference, however, exists with regard to the countries' welfare systems that comprise unemployment benefits, regulations for old age provisions, health insurance, and other social programs. Following a widely-used definition by EspingAndersen (1990), Germany is usually seen as a conservative welfare regime that is characterized by the protection of workers against a serious decline in their living standard due to job loss, disability, or retirement. Someone who is unemployed receives about two-thirds of his or her net income as a transfer payment for up to 12 months and is then eligible for temporarily unlimited welfare payments that cover 
basic subsistence and appropriate housing, depending on family size. Poland, in contrast, has a unique post-socialist welfare regime with strong (neo-)liberal elements. Labor market policies are rather passive and social protection is only moderate. Someone who becomes unemployed, for example, receives transfers for a limited period of six months only and then no further support from the state. The differences in the welfare regimes are particularly clear when one considers that social transfers in Germany amounted to 7,836 EUR per capita in 2009 as compared to only 1,383 EUR per capita in Poland.

The structural differences in social security (which also reflect differences in the access to opportunities and other resources as a function of the different economic strength of the two countries) might be responsible for the differences that we have found in the pattern of variables predicting engagement and disengagement strategies for dealing with demands of social change. Given the generally lower welfare protection in Poland as compared to Germany, demands are more existentially threatening for Polish individuals who are left little choice but to simply engage with them. Secondary appraisals in terms of controllability, however, were still relevant, since it does not make any sense to engage with a demand that is out of one's control, regardless of how existential the threat might be. Only for disengagement as the strategy of last resort, appraisal starts becoming relevant. Individuals then disengage more from threatening demands, probably because such demands produce anxiety; and they disengage more from demands that they consider to bring gains anyway, probably in order to selectively optimize the investment of their resources.

\section{Limitations}

The central limitation of the present study lies in its correlational nature, which does not allow us to draw strong conclusions concerning the direction of the effects. Thus, it is justifiable to ask, for example, whether being outside the labor market leads to a decline in engagement or whether low engagement makes it more likely to be crowded out of the labor market. Most likely, both effects work together, and longitudinal data is necessary to further elucidate the process of negotiating the demands. 
Another limitation of our study is that our analyses had to rely exclusively on self-reports and that, in most cases, survey inquiries were single-item measures so that we had no information about more objective and reliable indicators of the controllability of demands. This limitation, however, is not critical because we were explicitly interested in subjective appraisals. Subjective appraisals seem to be more important for predicting behavior than objective conditions (see Martin \& Westerhof, 2003) and can be reliably assessed with single questions (see Campbell, Converse, \& Rodgers, 1976).

Probably more problematic is the fact that, for the purpose of consistent replication between the German and the Polish samples, we did not consider theoretically-interesting resource variables, such as educational level or optimism, that might have been predictive for primary and secondary control strategies. This was a deliberate decision based on the idea that interindividual differences in primary, and especially secondary, appraisals should capture most of the interindividual differences in the possession of psychologically effective resources. For the purpose of consistency, we used demands that were identified and worded for the German context. Although we checked the plausibility of the items against theoretical and empirical evidence, the selection does not necessarily reflect the most salient work-related demands in Poland. Analyses published elsewhere, however, suggest that the demands are both structurally and functionally highly equivalent in the two countries (e.g., Obschonka, Silbereisen, \& Wasilewski, 2012). We do not have the same direct evidence concerning the functional equivalence of other scales and items used. However, in order to minimize the disadvantages of a study design that is an imposed etic, we carefully selected the scales and variables by consulting literature as well as experts from various psychological disciplines in the Polish research team with whom we organized two workshops to discuss possible differences.

\section{Future Directions}

The motivational theory of lifespan development presented by Heckhausen et al. (2010) posits a universal preference of humans to maximize their primary control capacity over the lifespan and across different domains of functioning. In other words, individuals are genuinely motivated to be in control of 
their environment because only then are their developmental capacities able to become fully expressed. This does not, however, mean that primary control strategies are always preferred or always adaptive. Heckhausen et al. suggest that, on the contrary, it is the congruence between internal resources and external opportunities on the one hand, and engagement and disengagement control strategies on the other hand, that is most adaptive. A growing body of empirical research supports this congruence theorem, including studies that have investigated engagement with, and disengagement from, demands of social change as a function of the different control beliefs that individuals hold and different opportunities in the social ecology (e.g., Grümer, Silbereisen, \& Heckhausen, in press; Tomasik \& Silbereisen, 2012a; Tomasik, Silbereisen, \& Heckhausen, 2010). Future research should focus on this congruence as the outcome variable in order to discover what groups will most adaptively engage or disengage under which conditions. This, of course, would require the measurement of external opportunity structures for mastering demands of social change, as well as other personal resources, that could moderate these structures. These resources might comprise the individuals' employment sector (e.g., public services, computer industries, etc.), occupational standing (e.g., manager, professional, etc.), or history of advanced training.

\section{Conclusion}

Based on the findings of this study, we conclude that, on average, people confronted with social change turn to active attempts to resolve strains rather than trying to disengage from them. Social change, such as globalization, individualization, and population aging are mainly conceived as significant and non-ignorable obstacles to the achievement of work-related developmental tasks in adulthood. Perceived controllability of the demands seems to be decisive in determining whether people engage with the demands imposed by social change, across different countries (see Tomasik, Silbereisen, \& Pinquart, 2010), and across different age groups (see Tomasik \& Silbereisen, 2011). Our findings demonstrate that people are not likely to engage unless they see themselves as capable of mastering the demands. We are convinced that perceived controllability is the key variable for social 
interventions and social policies aimed at promoting productive engagement with demands of social change.

At the individual level, promoting personal control beliefs about social change is one possible way to achieve more engagement with demands; however, this is a long-term process that would require costly individual interventions. A more efficient and probably more effective method would be to promote the actual controllability of the demands by adjusting national polices and institutional practices so that people have more control of their lives. To achieve this, national policies could comprise more flexible regulations for starting and ending employment and self-employment, institutional and legislative provisions that help to combine work and family responsibilities, and promotion of life-long learning opportunities. Effective practices and policies in the workplace could include further education that fosters the functional flexibility of employees within the company, more open communication by managers regarding the company's current plans and prospects, and simpler hiring and promotion practices within the internal labor markets of larger companies. Taken together, these measures could change people's appraisal of controllability and motivate them to engage actively in meeting the demands of social change. 


\section{References}

Bodenmann, G. (1995). A systemic-transactional conceptualization of stress and coping in couples. Swiss Journal of Psychology, 54, 34-49.

Brandtstädter, J., \& Renner, G. (1990). Tenacious goal pursuit and flexible goal adjustment: Explication and age-related analysis of assimilative and accommodative strategies of coping. Psychology and Aging, 5, 58-67.

Campbell, A., Converse, P. E., \& Rodgers, W. L. (1976). The quality of American life: Perceptions, evaluations, and satisfaction. New York: McGraw-Hill.

Eccles, J. S., \& Wigfield, A. (2002). Motivational beliefs, values, and goals. Annual Review of Psychology, 53, 109-132. doi: 10.1146/annurev.psych.53.100901.135153

Edwards, J. R. (1992). A cybernetic theory of stress, coping, and well-being in organizations. The Academy of Management Review, 17, 238-274.

Esping-Andersen, G. (1990). The three worlds of welfare capitalism. Cambridge, UK: Polity Press.

Folkman, S. \& Lazarus, R. S. (1980). An analysis of coping in a middle-aged community sample. Journal of Health and Social Behavior, 21, 219-229.

Folkman, S., Lazarus, R. S., Dunkel-Schetter, C., DeLongis, A., \& Gruen, R. J. (1986). Dynamics of stressful encounter: Cognitive appraisal, coping, and encounter outcomes. Journal of Personality and Social Psychology, 50, 992-1003.

Frydenberg, E., Lewis, R., Kennedy, G., Ardila, R., Frindte, W., \& Hannoun, R. (2003). Coping with concerns: An exploratory comparison of Australian, Colombian, German, and Palestinian adolescents. Journal of Youth and Adolescence, 32, 59-66.

Grümer, S., \& Pinquart, M. (2011). Perceived changes in personal circumstances related to social change: Associations with psychosocial resources and depressive symptoms. European Psychologist, 16, 68-78.

Grümer, S., Silbereisen, R. K., \& Heckhausen, J. (in press). Subjective well-being in times of social 
change: Congruence of control strategies and perceived control. International Journal of Psychology.

Heckhausen, J., \& Schulz, R. (1999). The primacy of primary control is a human universal: A reply to Gould's (1999) critique of the lifespan theory of control. Psychological Review, 106, 605-609. Heckhausen, J., Wrosch, C., \& Schulz, R. (2010). A motivational theory of lifespan development. Psychological Review, 117, 32-60.

Hobfoll, S. E. (1989). Conservation of resources: A new attempt at conceptualizing stress. American Psychologist, 44, 513-524.

Holahan, C. J., \& Moos, R. H. (1987). Personal and contextual determinants of coping strategies. Journal of Personality and Social Psychology, 52, 946-955.

Hu, L. T., \& Bentler, P. M. (1999). Cutoff criteria for fit indices in covariance structure analysis: Conventional criteria versus new alternatives. Structural Equation Modeling, 6, 1-55.

Kessler, R. C., \& McLeod, J. D. (1985). Social support and psychological distress in community surveys. In S. Cohen and S. L. Syme (eds.), Social support and health (pp. 19-40). New York: Academic Press.

Kohn, M. L. (2010). Class, stratification, and personality under conditions of apparent social stability and of radical social change: A multi-nation comparison. In R. K. Silbereisen \& X. Chen (Eds.), Social change and human development: Concept and results (p. 190-208). London: SAGE Publications.

Kohn, M. L. Slomcyznski, K. M., \& Schoenbach, C. (1990). Social structure and self-direction: A comparative analysis of the United States and Poland. Oxford, United Kingdom: Basil Blackwell.

Latack, J. C., Kinicki, A. J., \& Prussia, G. E. (1995). An integrative model of coping with job loss. The Academy of Management Review, 20, 311-342.

Lazarus, R. S. (1991). Emotion and adaptation. New York: Oxford University Press. 
Lazarus, R. S., \& Folkman, S. (1984). Stress, appraisal and coping. New York: Springer.

Lechner, C. M., Tomasik, M. J., Silbereisen, R. K., \& Wasilewski, J. (in press). Exploring the stressbuffering effects of religiousness in relation to social and economic change: Evidence from Poland. Psychology of Religion and Spirituality.

MacCallum, R. C., Browne, M. W., \& Sugawara, H. M. (1996). Power analysis and determination of sample size for covariance structure modeling. Psychological Methods, 1, 130-149.

Marcussen, K. (2005). Explaining differences in mental health between married and cohabiting individuals. Social Psychology Quarterly, 68, 239-257.

Martin, M., \& Westerhof, G. J. (2003). Do you need to have them or should you believe you have them? Resources, their appraisal, and well-being in adulthood. Journal of Adult Development, 10, 99112.

McCrae, R. R. (1984). Situational determinants of coping responses: Loss, threat, and challenge. Journal of Personality and Social Psychology, 46, 919-928.

Mills, M., \& Blossfeld, H.-P. (2003). Globalization, uncertainties and changes in the early life courses. Zeitschrift für Erziehungswissenschaft, 6, 188-218.

Obschonka, M., Silbereisen, R. K., \& Wasilewski, J. (2012). Constellations of new demands concerning careers and jobs: Results from a two-country study on social and economic change. Journal of Vocational Behavior, 80, 211-223.

Pearlin, L. I., Menaghan, E. G., Lieberman, M. A., \& Mullan, J. T. (1981). The stress process. Journal of Health and Social Behavior, 22, 337-356.

Pinquart, M., \& Silbereisen, R. K. (2008). Coping with increased uncertainty in the field of work and family life. International Journal of Stress Management, 15, 209-221.

Poulin, M., Haase, C. M., \& Heckhausen, J. (2005). Engagement and disengagement across the life span: An analysis of two-process models of developmental regulation. In W. Greve, K. Rothermund \& D. Wentura (Eds.), The adaptive self: Personal continuity and intentional self- 
development (pp. 117-135). Göttingen, Germany: Hogrefe.

Rosario, M., Shinn, M., Morch, H., \& Huckabee, C. B. (1988). Gender differences in coping and social supports: Testing socialization and role constraint theories. Journal of Community Psychology, 16, 55-69.

Scheier, M. F., Weintraub, J. K., \& Carver, C. S. (1986). Coping with stress: Divergent strategies of optimists and pessimists. Journal of Personality and Social Psychology, 51, 1257-1262.

Seiffge-Krenke, I. (2011). Coping with relationship stressors: A decade review. Journal of Research on Adolescence, 21, 196-210.

Seiffge-Krenke, I., Molinar, R., Ciariano, S., Menna, P., Michel, G., Hoareau, E., et al. (2010).

Competence in coping with future-related stress in adolescents from France, Italy, Great Britain, and Germany. Journal of Happiness Studies, 11, 703-720.

Silbereisen, R. K., \& Pinquart, M. (Eds.). (2008). Individuum und sozialer Wandel: Eine Studie zu Anforderungen, psychosozialen Ressourcen und individueller Bewältigung. Weinheim: Juventa.

Sinclair, R. R., Sears, L. E., Probst, T., \& Zajack, M. (2010). A multilevel model of economic stress and employee well-being. In J. Houdmont \& S. Leka (Eds.), Contemporary health psychology: Global perspectives on research and practice (p. 1-21). Hoboken, NJ: Wiley-Blackwell.

Steiger, J. H. (1990). Structural model evaluation and modification: An interval estimation approach. Multivariate Behavioral Research, 25, 173-180.

Tamres, L. K., Janicki, D., \& Helgeson, V. S. (2002). Sex differences in coping behavior: A metaanalytic review and an examination of relative coping. Personality and Social Psychology Review, $6,2-30$

Taylor, S. E., Klein, L. C., Lewis, B. P., Gruenewald, T. L., Gurung, R. A. R., \& Updegraff, J. A. (2000). Biobehavioral responses to stress in females: Tend-and-befriend, not fight-or-flight. Psychological Review, 107, 411-429.

Tesch-Römer, C., Motel-Klingebiel, A., \& Tomasik, M. J. (2008). Gender differences in subjective 
well-being: Comparing societies with respect to gender equality. Social Indicators Research, 85, 329-349.

Thoits, P. A. (1995). Stress, coping, and social support processes: Where are we? What next? Journal of Health and Social Behavior, 35, 53-79.

Thoits, P. A. (2006). Personal agency in the stress process. Journal of Health and Social Behavior, 47, 309-323.

Tomasik, M. J., Pavlova, M. K., Lechner, C. M., Blumethal, A., Körner, A. (2012). Changing contexts of youth development: An overview of recent social trends and a psychological model. New Directions for Youth Development, 135, 14-25.

Tomasik, M. J., Sijko, K., Silbereisen, R. K., \& Wasilewski, J. (2013). Demands of social change in different niches and regions of Poland. Manuscript in preparation.

Tomasik, M. J. \& Silbereisen, R. K. (2009). Demands of social change as a function of the political context, institutional filters, and psychosocial resources. Social Indicators Research, 94, 13-28.

Tomasik, M. J., \& Silbereisen, R. K. (in press). Negotiating the demands of active ageing: Longitudinal findings from Germany. Ageing and Society.

Tomasik, M. J., \& Silbereisen, R. K. (2012a). Beneficial effects of disengagement from futile struggles with occupational planning: A contextualist-motivational approach Developmental Psychology, 48, 1785-1796.

Tomasik, M. J., \& Silbereisen, R. K (2012b). Social change and adolescent developmental tasks: The case of post-communist Europe. Child Development Perspectives, 6, 326-334..

Tomasik, M. J., Silbereisen, R. K., \& Heckhausen, J. (2010). Is it adaptive to disengage from demands of social change? Adjustment to developmental barriers in opportunity-deprived regions. Motivation and Emotion, 34, 384-398.

Tomasik, M. J., Silbereisen, R. K., \& Pinquart, M. (2010). Individuals negotiating demands of social and economic change: A control-theoretical approach. European Psychologist, 15, 246-259. 
Valentiner, D. P., Holohan, C. J., \& Moos, R. H. (1994). Social support, appraisals of event controllability, and coping: An integrative model. Journal of Personality and Social Psychology, $66,1094-1102$.

Voydanoff, P. (1990). Economic distress and family relations: A review of the eighties. Journal of Marriage and the Family, 52, 1099-1115.

Waters, L. E. (2000). Coping with unemployment: A literature review and presentation of a new model. International Journal of Management Reviews, 2, 169-182.

Wurm, S., Tomasik, M. J., \& Tesch-Römer, C. (2010). On the importance of a positive view on aging for physical activity among older adults: Cross-sectional and longitudinal findings. Psychology and Health, 25, 25-42. 


\section{Footnotes}

${ }^{1}$ The conceptualization of engagement and disengagement can also be found in other two-process models that distinguish between assimilation and accommodation (Brandtstädter \& Renner, 1990), problem- and emotion-focused coping (Folkman \& Lazarus, 1980), and active and avoidance coping (Holahan \& Moos, 1987). These models, however, are based on different theoretical assumptions that sometimes lead to different predictions (for a detailed discussion, see Poulin, Haase, \& Heckhausen, 2005).

${ }^{2}$ We would like to thank an anonymous reviewer for pointing out this interpretation. 
Author Notes

The research project, Sociological and Psychological Determinants of Negotiating Rapid Social Changes, was funded by the Polish Ministry of Science and Higher Education (PI: Prof. Dr. Jacek Wasilewski, grant no. N 116 107734). The Jena Study on Social Change and Human Development in Germany was funded by the German Research Foundation (DFG) as a subproject (PI: Prof. Dr. Rainer K. Silbereisen, grant no. SFB580-04-C6) of the Collaborative Research Center 580 "Social Developments in Post-Socialistic Societies: Discontinuity, Tradition, and Structural Formation." We would like to express our deepest thanks to everyone who volunteered to participate in the study.

Address correspondence and reprint requests to Martin J. Tomasik, University of Zurich, Department of Psychology, Applied Psychology: Life Management, Binzmühlestrasse 14, Postfach 11, 8050 Zürich, Switzerland. Email: tomasik@psychologie.uzh.ch 